\title{
WCIP Method Applied To Modeling an L- Notched Rectangular Metallic Ring FSS for Multiband Applications and its Equivalent Structure
}

\author{
Ibtissem Adoui ${ }^{1}$, Mohammed Titaouine ${ }^{1,2}$, Hassina Choutri ${ }^{1}$, Raouia Saidi ${ }^{2}$, Thayuan Rolim De \\ Sousa $^{3}$, Alfredo Gomes Neto ${ }^{3}$, Henri Baudrand ${ }^{4}$ \\ ${ }^{1}$ Laboratory of Materials and Electronic Systems LMSE, University of BordjBou-Arréridj, El Anasseur 34625, \\ Algeria. \\ ibtissem.adoui@gmail.com,benzhch38@gmail.com \\ ${ }^{2}$ Department of electronics, Faculty of technology, University of Batna2, Batna 05000, Algeria. \\ mohammedtitaouine@gmail.com,saidiraouia@gmail.com \\ ${ }^{3}$ Group of Telecommunications and Applied Electromagnetism, GTEMA, Federal Institute of Education, \\ Science and Technology of Paraiba, IFPB, Av. 1 de Maio, 720, João Pessoa, PB, Brazil, CEP 58015-430 \\ thayuan.rolim@gmail.com,alfredogomesjpa@gmail.com \\ ${ }^{4}$ University of Toulouse; INPT, UPS; LAPLACE; ENSEEIHT, 2 rue Charles Camichel, BP 7122, F-31071 \\ Toulouse cedex 7, France. \\ henri.baudrand@yahoo.fr
}

\begin{abstract}
A frequency selective surface (FSS) with a unit cell containing of an L-notched rectangular metallic ring pattern that can be adopted for dual polarization applications is proposed and analyzed using the wave concept iterative procedure (WCIP). The parametric study of the FSS provides three FSS dimensions where their variation independently or simultaneously results in resonant frequencies tuning. They are the two dimensions of the $L$ part of the FSS and its notch penetration and changing their values in the FSS allowed intervals gives rise to charts and equations based on polynomials determined by the use of least mean square method. Thus no need to software to determine the FSS resonant frequencies once the application is restricted to a specific FSS such as the Lnotched rectangular metallic ring FSS for low cost FSS use. The presented synthesis approach is extended to the determination of the equivalent FSS structures based on non-coupled parallel metallic strips for the complex FSS structures of difficult comprehensive resonance sources. One FSS is manufactured and characterized. A good agreement is recorded when the WCIP results for the transmission coefficient are compared with the results of COMSOL Multiphysics software and measurement.
\end{abstract}

Index Terms - FSS, WCIP, multiband, equivalent circuit, FSS synthesis approach, complex FSS equivalent structure. 


\section{INTRODUCTION}

Commonly, Frequency Selective Surfaces (FSSs) consist of a two-dimensional periodic array of a metal plane aperture with openings (metal grid), or an arrangement of printed conductive elements on a dielectric substrate and they act as a band-pass or band-stop filter [1],[2]. For the last few decades, FSS are one of the important planar periodic structures, which are investigated and characterized in several important applications domain such as electromagnetic engineering and microwaves. Due to large demands for multi-functionality of FSS in electrical engineering and telecommunications, many researchers studied and developed the FSS for designing multiband responses[3]-[15].

In this paper, we propose a structure having five resonant frequencies, three resonant when the FSS is $x$-polarized and two resonant when the FSS is $y$-polarized. To perform this investigation, the proposed FSS was simulated using the wave concept iterative procedure WCIP [16].

In order to validate the results of the WCIP method, the commercial finite-element software package COMSOL Multiphysics RF Module is employed, and one FSS design is fabricated and tested. The obtained WCIP and COMSOL Multiphysics results are in good agreement where compared with the experimental ones.

Moreover, for such FSS structure, a synthesis approach based on the FSS parametric study allows the determination of the resonant frequencies. The use of the least mean square method allowed the determination of the resonant frequencies equations based on polynomials and plotting charts. For complex FSS patterns characterized with a difficult resonant frequencies behavior comprehension, the synthesis approach is extended to FSS structures based on non-coupled parallel metallic strips to provide complex FSS equivalents structures. When the FSS applications are limited to the use of an FSS of a specific pattern, abacuses are implemented to get a direct determination of the FSS resonant frequencies ones the FSS dimensions are fixed without a need to run the software each time. The presented FSS synthesis approach results are compared to the WCIP results, COMSOL Multiphysics and measurements and good agreement is obtained.

\section{L-NOTCHED RECTANGULAR METALLIC RING FSS DESIGN}

The unit cell of the L-notched rectangular metallic ring FSS is shown in fig.1 where the metallic ring is printed on a fiberglass (FR-4) substrate with dielectric constant $\varepsilon_{\mathrm{r}}=4.4$ and a thickness $\mathrm{h}=1$ $\mathrm{mm}$.

The transmission characteristic of the proposed multiband FSS is determined by the WCIP method when the interface of the FSS is described by $200 \times 200$ pixels, and the iterative procedure is stopped after 600 iterations. The FSS is excited with a normal incident plane wave source. 


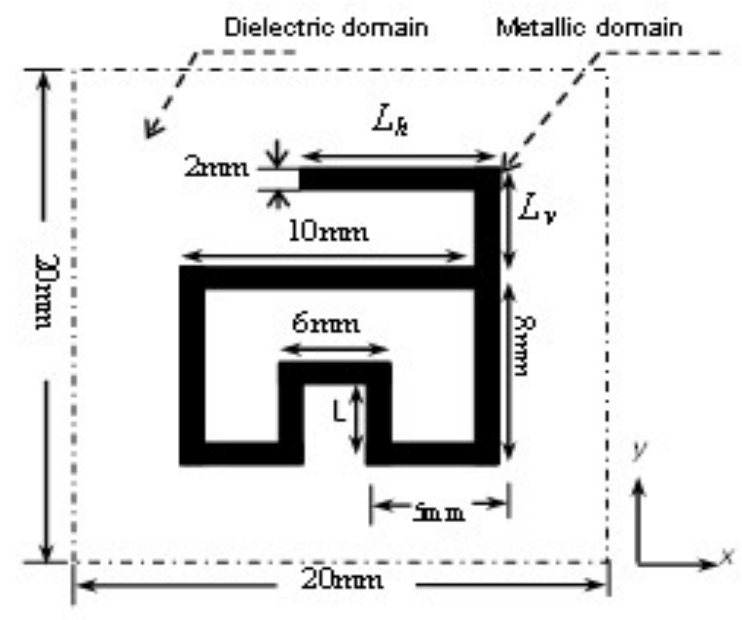

Fig.1. The L-notched rectangular metallic ring FSS unit cell.

\section{RESULTS AND DISCUSSIONS}

\section{A. WCIP results and validation}

In order to confirm the results obtained by WCIP method, a simulation with COMSOL Multiphysics software was investigated and one FSS prototype of $10 \times 10$ unit cells, shown in Fig. 2, is fabricated and experimentally characterized by using the data acquisition system that consists of an Agilent two ports microwave network analyzer N5230A and two standard horn antennas. The FSS overall size is $20 \mathrm{~cm} \times 20 \mathrm{~cm}$, and the metallic rings are printed on a substrate of FR-4 with thickness $\mathrm{h}=1 \mathrm{~mm}$ and dielectric constant $\varepsilon_{\mathrm{r}}=4.4$. All the other dimensions of the fabricated FSS are the same as those of the unit cell shown in Fig. 1 when $L_{h}=7.5 \mathrm{~mm}$ and $L_{v}=4 \mathrm{~mm}$.

Figs.3 (a) and (b) present the FSS transmission coefficient obtained by the WCIP method, COMSOL Multiphysics software, and measurements when a normally incident plane wave is $x$ polarized and $y$-polarized respectively.

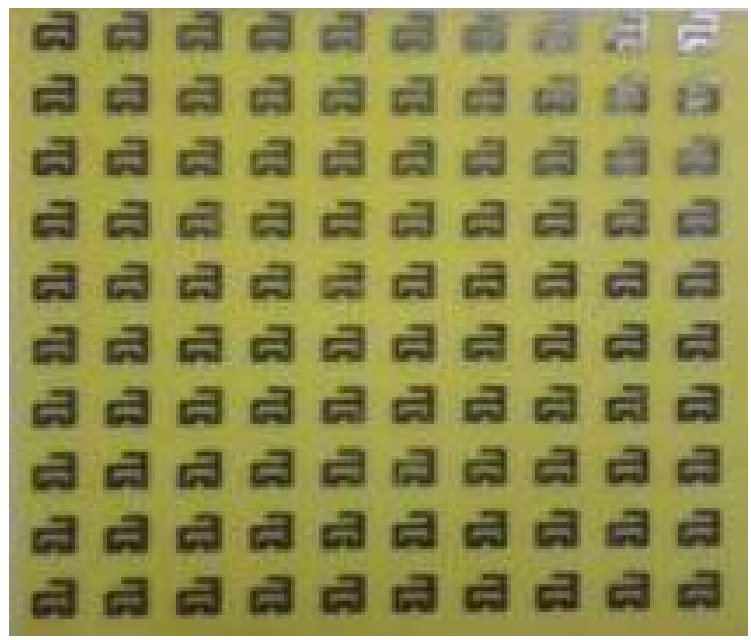

Fig.2.Fabricated FSS with an array of $10 \times 10$ unit cells. 
As the incident plane wave is $x$-polarized, dual resonant frequencies are observed, from both simulated WCIP, COMSOL Multiphysics and measured results. The first resonance occurs at 8.7 $\mathrm{GHz}$ in the WCIP results, $8.9 \mathrm{GHz}$ in the COMSOL results and $8.5 \mathrm{GHz}$ for measurements while the second resonance takes place at $10.4 \mathrm{GHz}, 10.3 \mathrm{GHz}$ and $10.1 \mathrm{GHz}$ for WCIP, COMSOL and measured results respectively. In the case of y-polarization, only one resonance frequency is observed at $8.1 \mathrm{GHz}$ as a WCIP result, $8.1 \mathrm{GHz}$ as a COMSOL result and $7.8 \mathrm{GHz}$ in measurements. A good agreement is noted when comparing the WCIP results with those of COMSOL Multiphysics and Measurement.

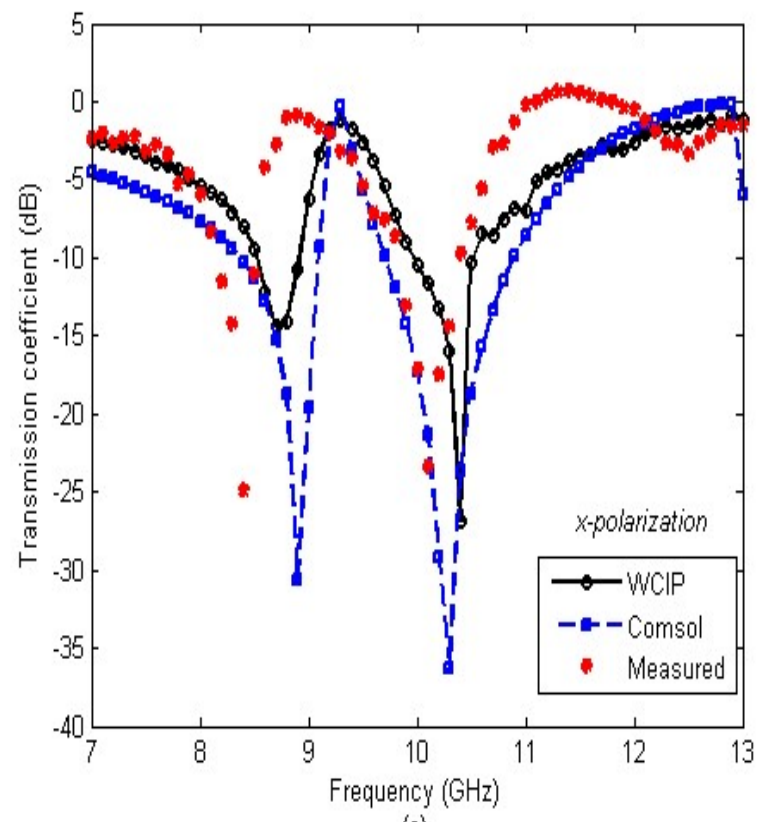

(a)

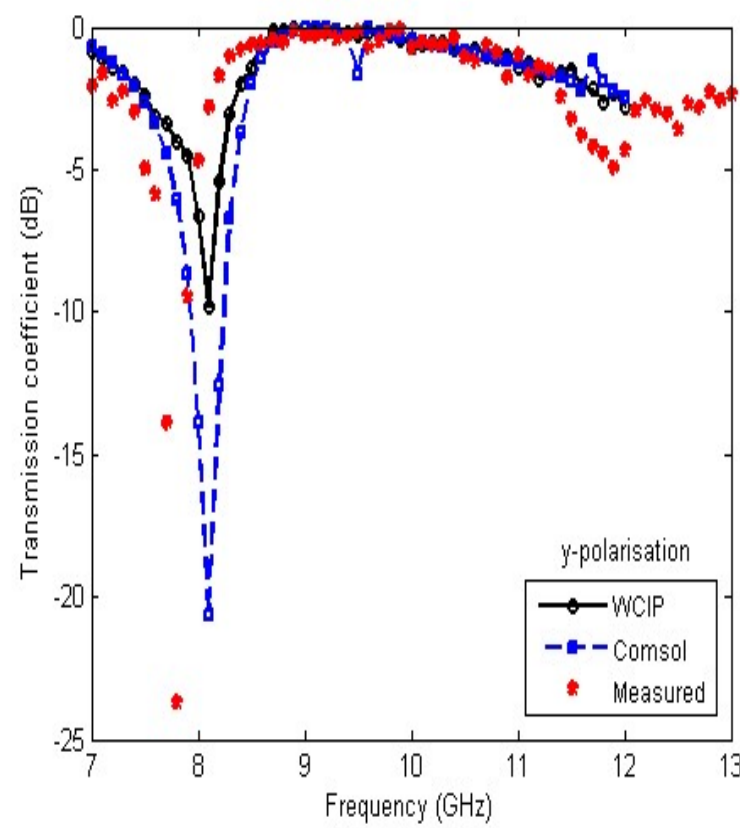

(b)

Fig.3. Measurements and simulated WCIP and COMSOL Multiphysics results of the dependence of the transmission coefficient to the operating frequency when $\mathrm{L}_{\mathrm{h}}=7.5 \mathrm{~mm}$, in the case of $x$-polarization(a) and $y$-polarization (b).

\section{B. L-notched FSS parametric study}

To determine the dimensions responsible of tuning the resonant frequencies for the dual polarized FSS, a parametric study should take place. Figs. 4 and 5 illustrate the transmission coefficient of the FSS when the parallel strip length $L_{h}$ varies from $4.5 \mathrm{~mm}$ to $7.5 \mathrm{~mm}$. With the increase in $L_{h}$ lengths, the highest and the lowest resonant frequencies decrease while the central resonant frequency remains constant not affected by the variation of the $\mathrm{L}_{\mathrm{h}}$ values in the considered interval when the $x$-polarized source is used.

Concerning the FSS $y$-polarized source case, when $\mathrm{L}_{\mathrm{h}}$ increases the lowest resonant frequency is shifted down, while the highest one remains constant. 


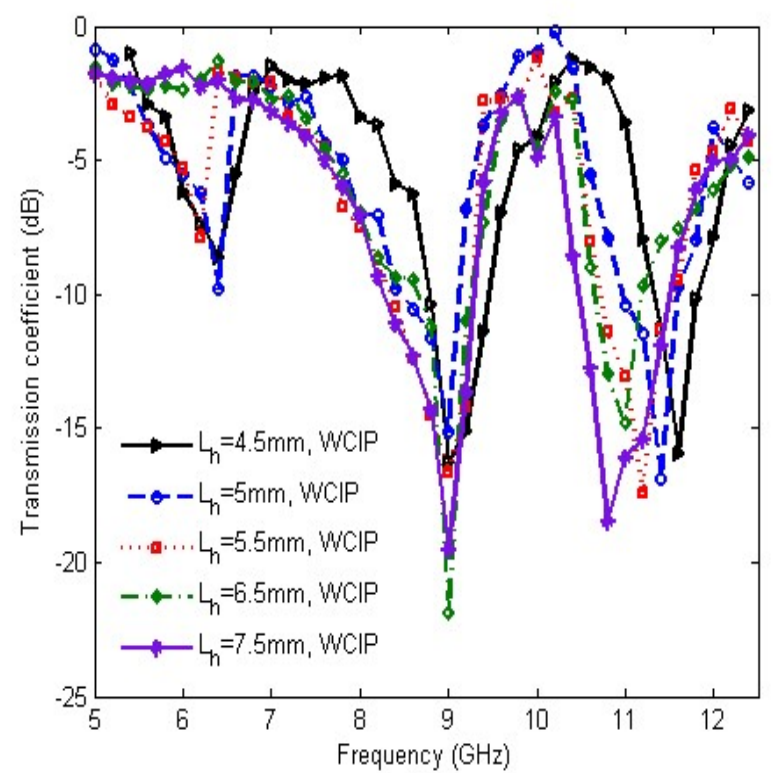

(a)

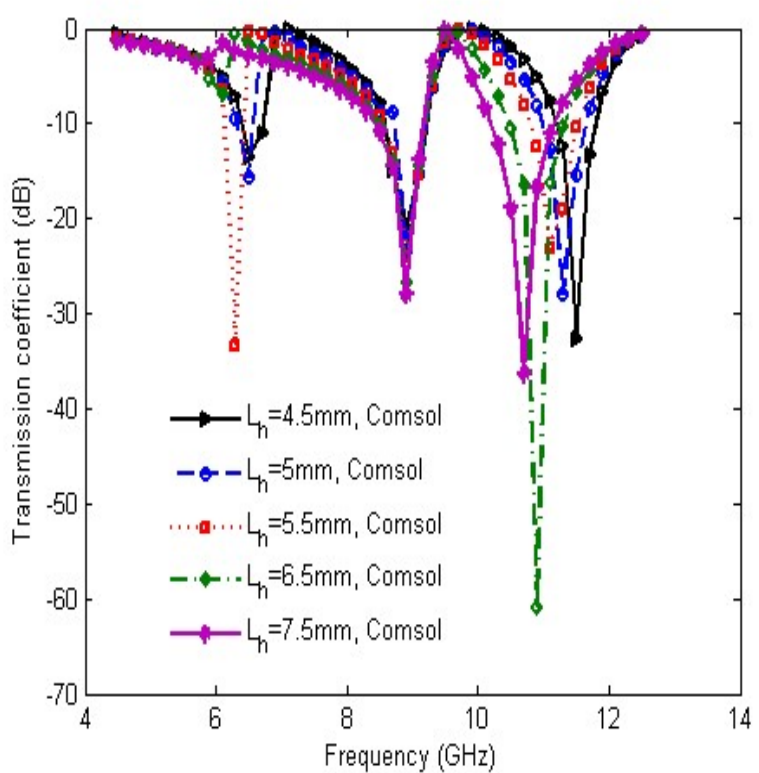

(b)

Fig.4.Transmission coefficient $\mathrm{S}_{21}$ versus the operating frequency for different lengths $\mathrm{Lh}_{\mathrm{h}}$ when the FSS is $x$ polarize(a)WCIP results, (b) COMSOL results.

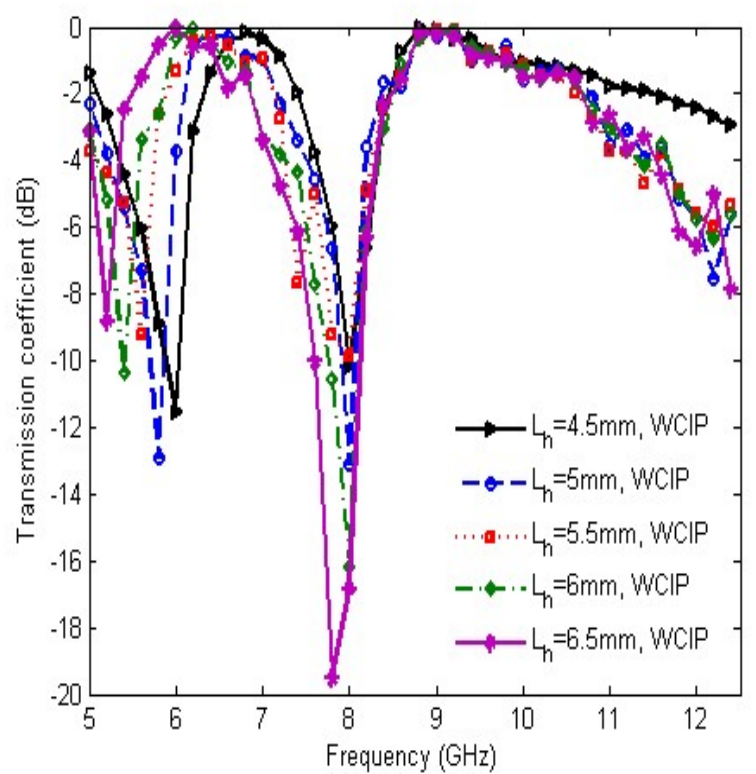

(a)

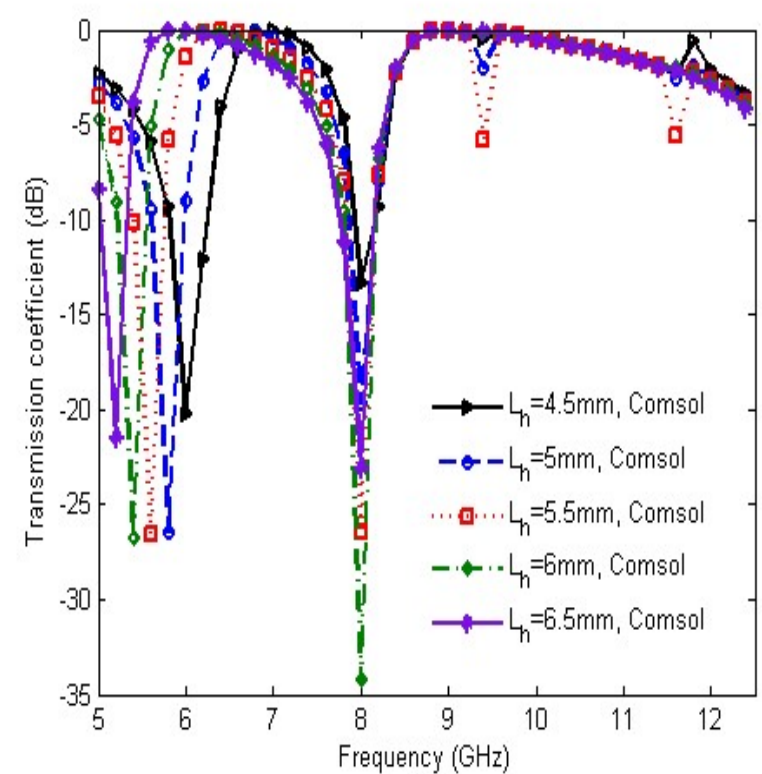

(b)

Fig.5. Transmission coefficient $\mathrm{S}_{21}$ versus the operating frequency for different lengths $\mathrm{L}_{\mathrm{h}}$ when the FSS is $y$-polarized.

(a)WCIP results, (b) COMSOL results. 
The effect of the vertical strip $L_{v}$ of the proposed FSS on the resonant frequencies is shown in Figs. 6 and 7 for $x$-polarization and $y$-polarization respectively. In the $x$-polarization case, when $\mathrm{L}_{\mathrm{v}}$ changes from $0.5 \mathrm{~mm}$ to $2.5 \mathrm{~mm}$, the lowest resonant frequency is decreased from about $8 \mathrm{GHz}$ to about 7GHz. The centered resonant frequency slightly decreases while the highest resonant frequencies remain constant. The results in Fig. 7 concern the $y$-polarization case and shows that the lowest resonant frequency decreases with the increase of $\mathrm{L}_{\mathrm{v}}$, while the highest one remains constant.
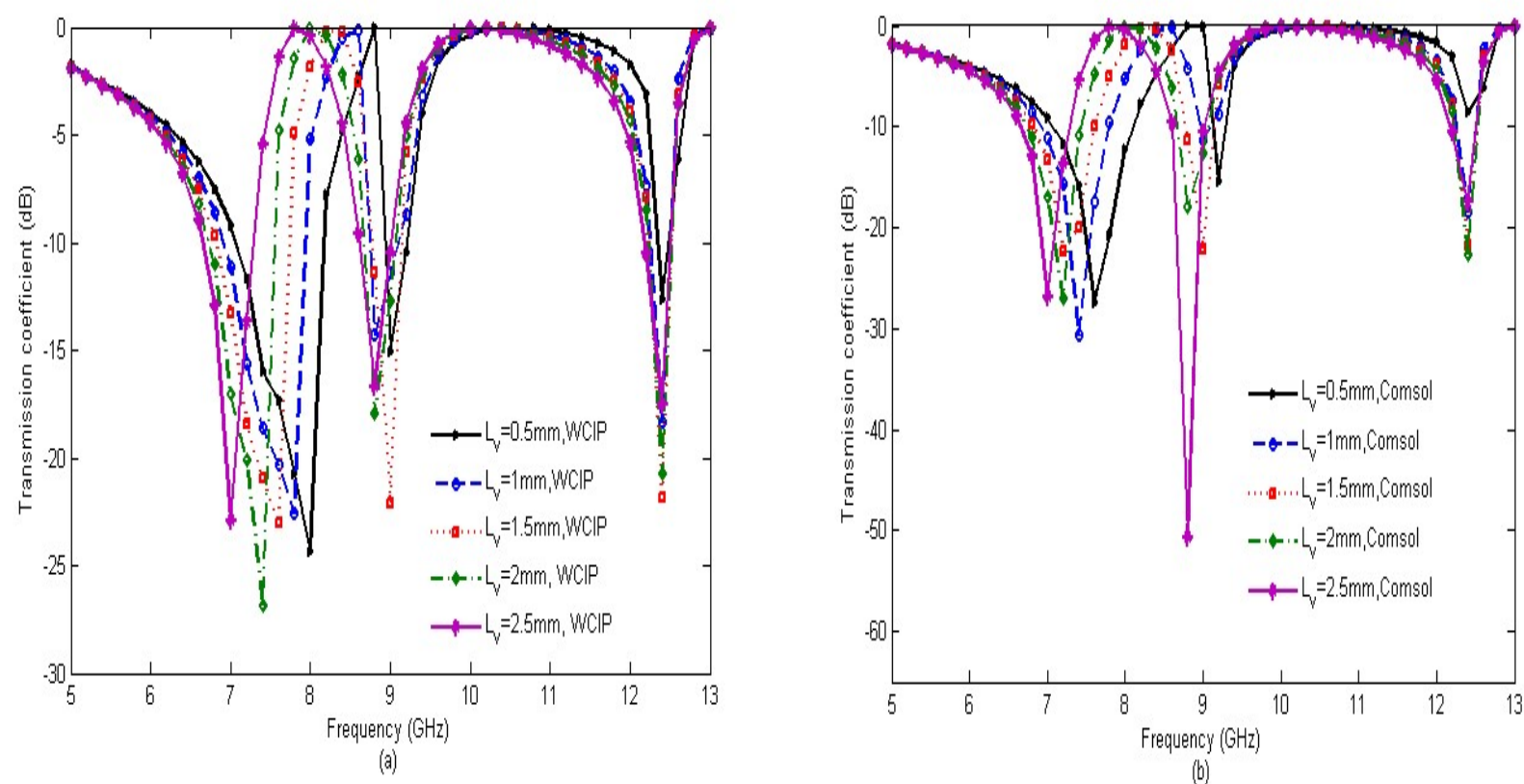

Fig. 6.Transmission coefficient $\mathrm{S}_{21}$ versus the operating frequency for different lengths $\mathrm{L}_{\mathrm{v}}$ when the FSS is $x$-polarized.

(a)WCIP results, (b) COMSOL results.
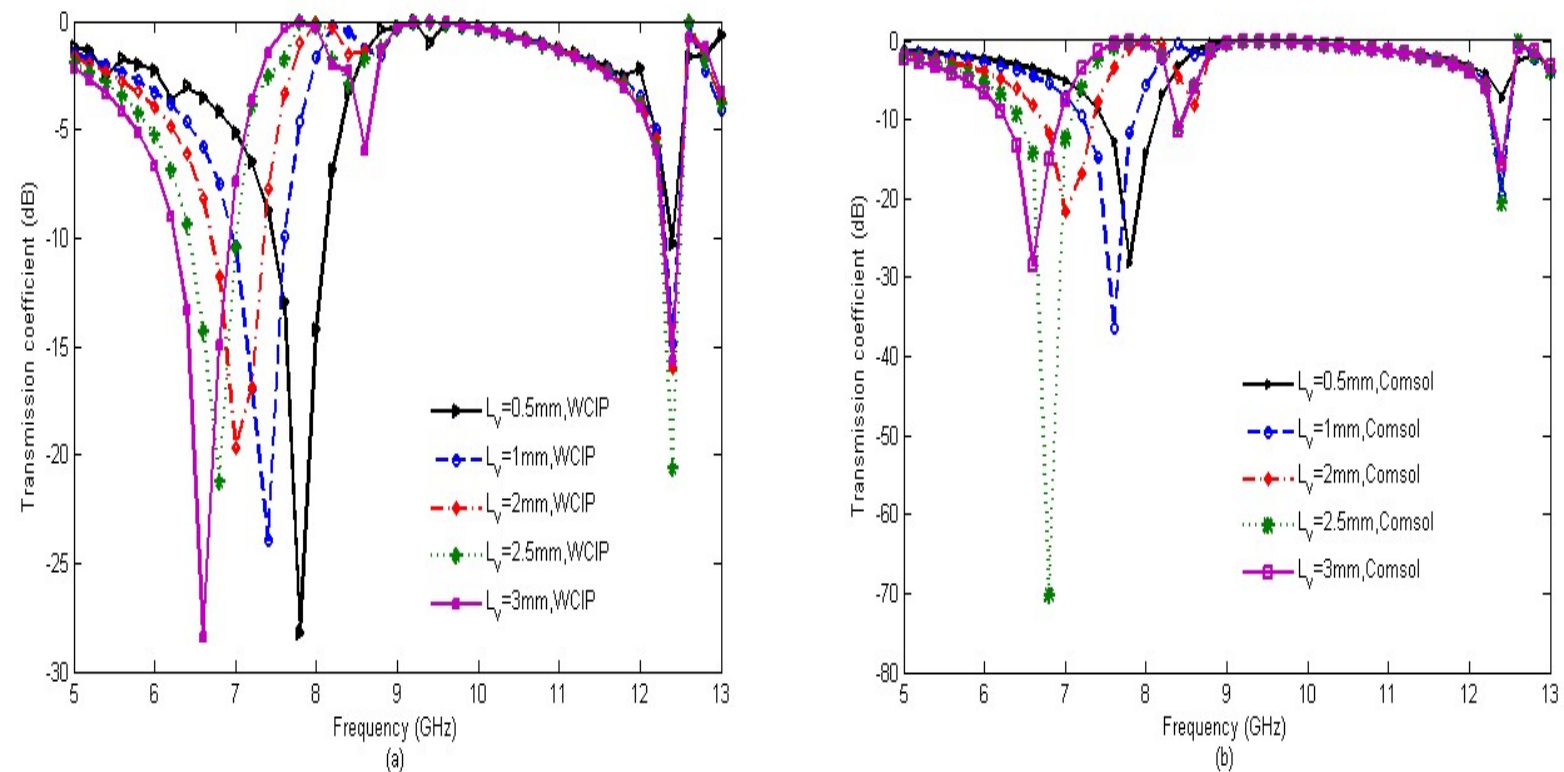

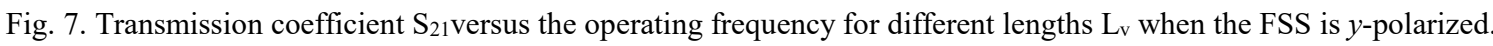

(a)WCIP results, (b) COMSOL results. 
The variation of $\mathrm{L}_{\mathrm{v}}$ can serve as a large tuning way for the lowest resonant frequency for both polarizations as it can serve also as a fine tuning way for the centered resonant frequency in the $x$ polarization.

Another important parameter, which affects the resonant frequencies of the proposed FSS, is the length $\mathrm{L}$ of the notch. Figs. 8 and 9 show the transmission coefficient due to the increase in L for $x$ polarization and $y$-polarization respectively.

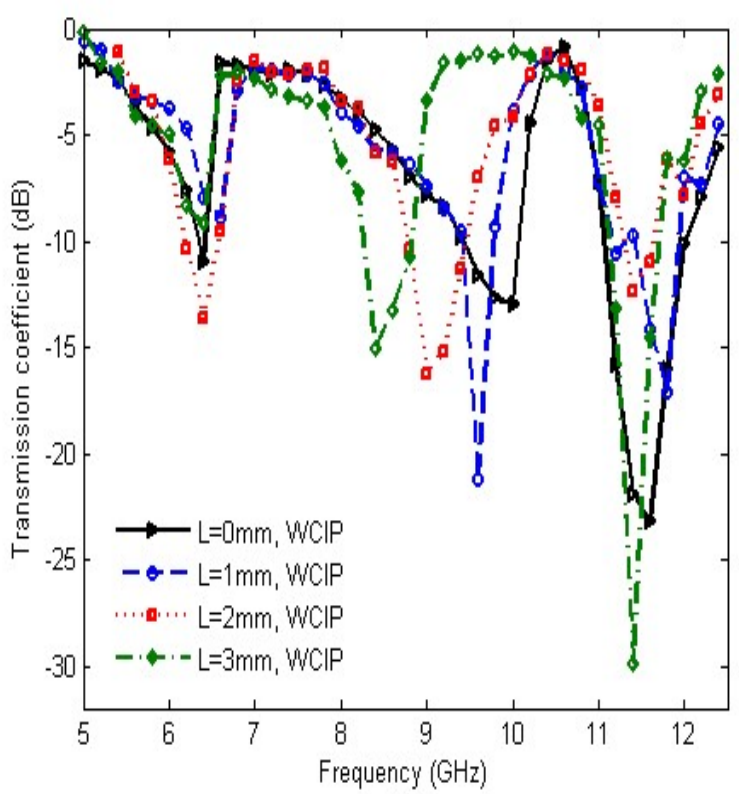

(a)

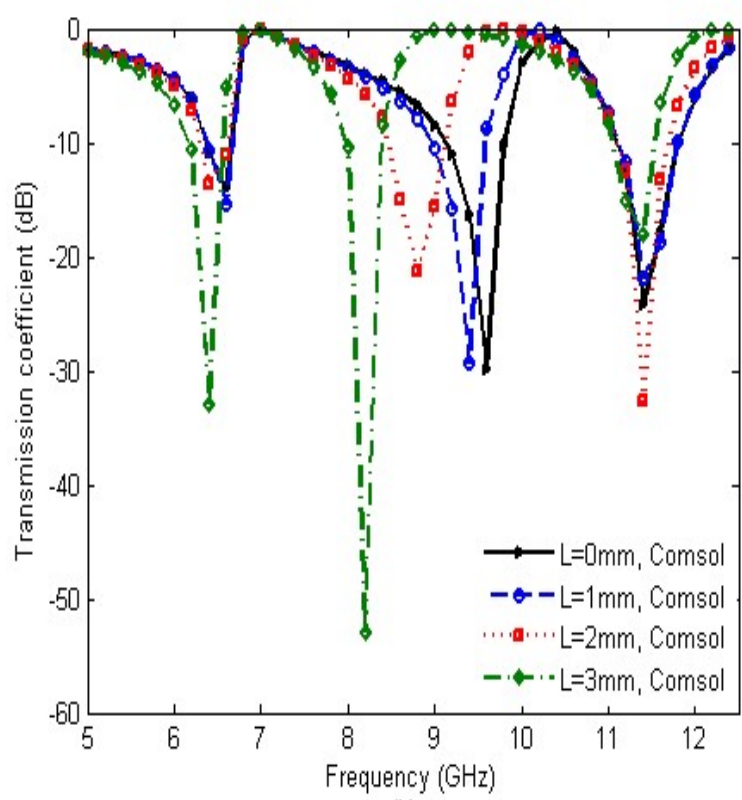

(b)

Fig. 8. Transmission coefficient $\mathrm{S}_{21}$ versus the operating frequency for different lengths L when the FSS is $x$-polarized.

(a)WCIP results, (b) COMSOL results.

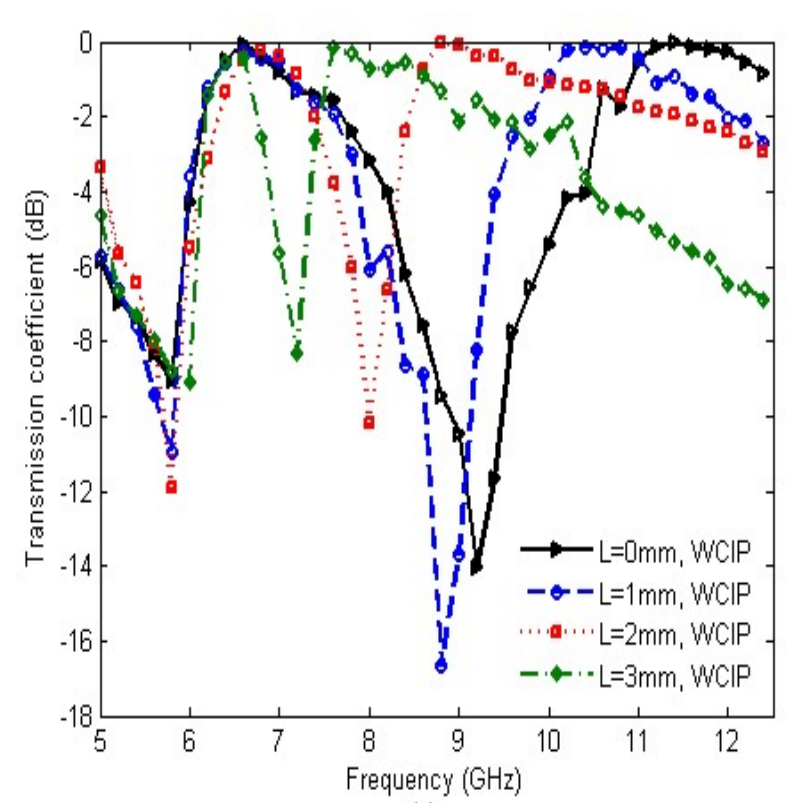

(a)

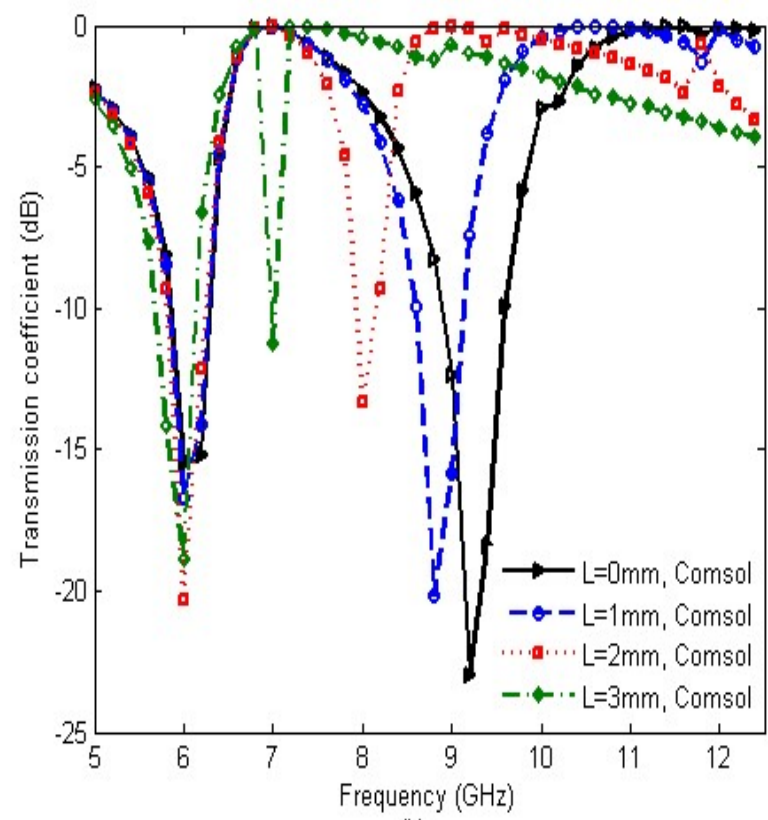

(b)

Fig. 9. Transmission coefficient $\mathrm{S}_{21}$ versus the operating frequency for different lengths L when the FSS is $y$-polarized.

(a)WCIP results, (b) COMSOL results 
As the values of $\mathrm{L}$ increase from 0 to $3 \mathrm{~mm}$, the central resonant frequency decreases from about $9.8 \mathrm{GHz}$ to $8.1 \mathrm{GHz}$ while both the lowest and the highest resonant frequencies do not change. In the case of $y$-polarization source plane wave, when the height $\mathrm{L}$ increases the highest resonant frequency decreases, while the lowest one remains constant.

\section{BANDWIDTH ENHANCEMENT}

The adjustment of different resonance frequencies can result in widening the FSS band by fusing two adjacent resonant frequencies bandwidth. In the case of $\mathrm{L}_{\mathrm{h}}=12 \mathrm{~mm}$ and the $\mathrm{x}$-polarized exciting source, the highest resonant frequency decreases and merges with the central resonant frequency resulting in only one resonant frequency as the lowest resonant frequency disappears and an improvement of the FSS bandwidth has shown in Fig. 10. The enhanced bandwidth is $6.95 \mathrm{GHz}$ at $3 \mathrm{~dB}$ and $3.25 \mathrm{GHz}$ at $-10 \mathrm{GHz}$ concerning the WCIP results.

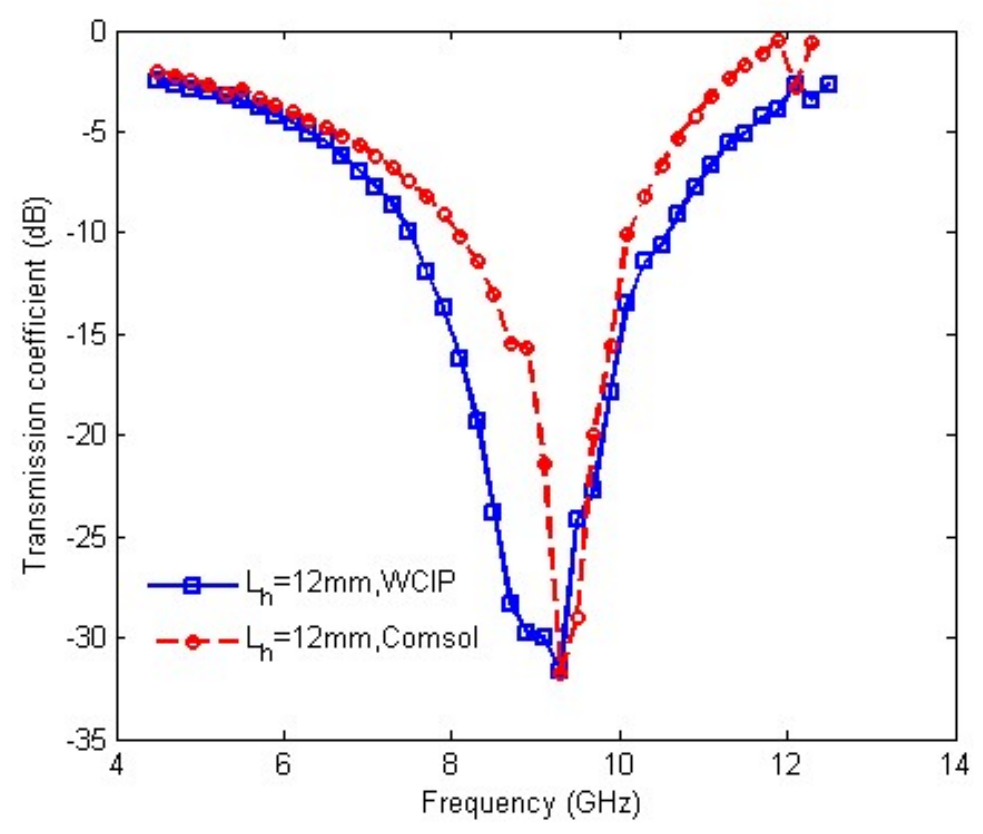

Fig.10. Transmission coefficient $\mathrm{S}_{21}$ versus the operating frequency when $\mathrm{L}_{h}=12 \mathrm{~mm}$ for the $x$-polarized FSS.

\section{RESONANT FREQUENCY ESTIMATION}

An approximate procedure can be used to estimate the resonant frequencies of the proposed geometry without using neither analytical nor numerical methods. The presented procedure is based on determining the length of the linear metallic strip shown in Fig. 11 equivalent to the complex pattern FSS for a given complex FSS dimension for the structure of Fig.1starting from the approximate equation providing an approximate evaluation of the resonant frequency of a linear microstrip structure of length $\mathrm{L}_{\mathrm{e}}$ given by [17]: 


$$
\mathrm{f}_{\mathrm{r}}=\frac{\mathrm{c}}{2 L_{e} \sqrt{\varepsilon_{\mathrm{reff}}}}
$$

$\mathrm{c}$ is the speed of light in free space given by $\mathrm{c}=3 \times 10^{8} \mathrm{~m} / \mathrm{s}$, L is the length of the metallic strip, and $\varepsilon_{\text {reff }}$ is the effective dielectric constant of the structure and can be calculated from the equation of microstrip lines as[18]:

$$
\varepsilon_{\mathrm{reff}}=\frac{\varepsilon_{\mathrm{r}}+1}{2}+\frac{\varepsilon_{\mathrm{r}}-1}{2}\left(1+12 \frac{\mathrm{h}}{\mathrm{W}}\right)^{-\frac{1}{2}}
$$

Where $\mathrm{W}$ is the metallic strips width $(\mathrm{W}=2 \mathrm{~mm}), \mathrm{h}$ is the thickness of the substrate taken here as $\mathrm{h}=1 \mathrm{~mm}$ due to their availability in the laboratory. Therefore, the value of the effective dielectric constant, in this case, is given as $\varepsilon_{\text {reff }}=3.3425$.

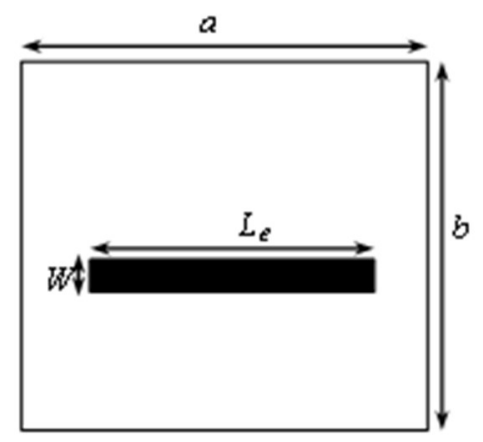

Fig. 11. metallic strip FSS unit cell with the effective strip's length.

First, the resonant frequencies for different values of the FSS dimension $\mathrm{L}_{\mathrm{h}}$ or $\mathrm{L}$ shown in Fig. 1 are determined by the WCIP method and the COMSOL Multiphysics software but maintaining the other FSS dimensions constant. Then, the different equivalent strips lengths called effective lengths $\mathrm{L}_{\mathrm{e}}$ are calculated using:

$$
\mathrm{L}_{\mathrm{e}}=\frac{\mathrm{c}}{2 f_{r} \sqrt{\varepsilon_{\mathrm{reff}}}}
$$

At this stage, the real metallic strips length that if manufactured gives the same result is not yet determined since it is related to the effective length $\mathrm{L}_{\mathrm{e}}$ by:

$$
\mathrm{L}_{\mathrm{e}}=\mathrm{L}_{\mathrm{r}} / \mathrm{k}
$$

Where $\mathrm{k}$ is a polynomial to be determined from the curve relating the complex FSS dimension $\mathrm{L}_{\mathrm{h}}$ or $\mathrm{L}$ and the effective length $\mathrm{L}_{\mathrm{e}}$ calculated in (3). Thus, it can be noted as $k\left(\mathrm{~L}_{h}\right)$ or $k(\mathrm{~L})$. Once determined, the resonant frequency of the FSS of Fig. 1is directly given by only inserting the concerned dimension $\mathrm{L}_{\mathrm{h}}$ or $\mathrm{L}$.

The polynomials are found by the resolutions of linear equations as a form of matrix systems $A^{*} \mathrm{X}=\mathrm{b}$. When the number of points used for determining the polynomial is equal to the order of the polynomial, the matrix $\mathrm{X}$ is square in this case the solution is unique. In the literature, there are 
many methods for optimization like the genetic algorithm, neural network, gradient method, least square method ... In the following, the optimization with the least square method of one variable on the resonance frequencies by using the Scilab software [19] is used. Therefore, knowing the two polynomials concerning the FSS dimensions $\mathrm{L}_{\mathrm{h}}$ and $\mathrm{L}$, the resonant frequency of the FSS structure of Figs. 1 and 2 can be easily anticipated only by knowing the values of the influencing dimensions $L_{h}$ and L, the dielectric without using neither the WCIP method nor the COMSOL Multiphysics or HFSS or other commercial software. The precise equation giving the FSS resonant frequency is then given by:

$$
\mathrm{f}_{\mathrm{r}_{-} \text {Estim }}=\mathrm{k}\left(\mathrm{L}_{\mathrm{h}}\right) \frac{\mathrm{c}}{2 \mathrm{~L}_{\mathrm{h}} \sqrt{\varepsilon_{\text {reff }}}}
$$

where $L_{h}$ is the varied dimension FSS from the standard FSS dimensions shown in Fig. 1 in addition to the substrate thickness $\mathrm{h}=1 \mathrm{~mm}$ and its dielectric constant $\varepsilon_{\mathrm{r}}=4.4$.

$$
\mathrm{f}_{\mathrm{r}_{-} \text {Estim }}=\mathrm{k}(\mathrm{L}) \frac{\mathrm{c}}{2 \mathrm{~L} \sqrt{\varepsilon_{\text {reff }}}}
$$

where $\mathrm{L}$ is the varied dimension FSS from the standard FSS dimensions shown in Fig. 1 in addition to the substrate thickness $\mathrm{h}=1 \mathrm{~mm}$ and its dielectric constant $\varepsilon_{\mathrm{r}}=4.4$, and $c$ is the speed of light $\mathrm{c}=3 \times 10^{8} \mathrm{~m} / \mathrm{s}$.

Fig.12 shows the five resonant frequencies in function of the length affecting the FSS resonance obtained by the WCIP method, COMSOL Multiphysics software and equation 5. By comparison, a good agreement is observed.

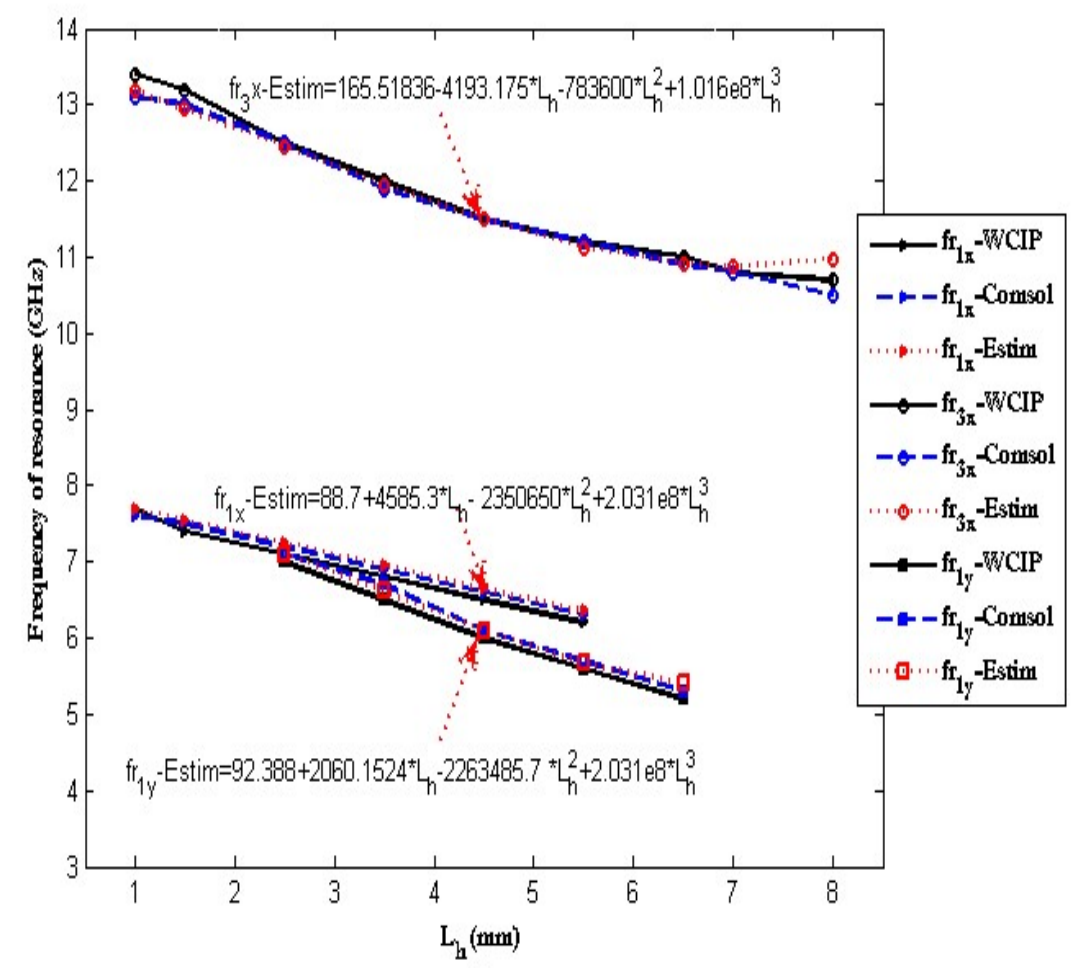

(a) 


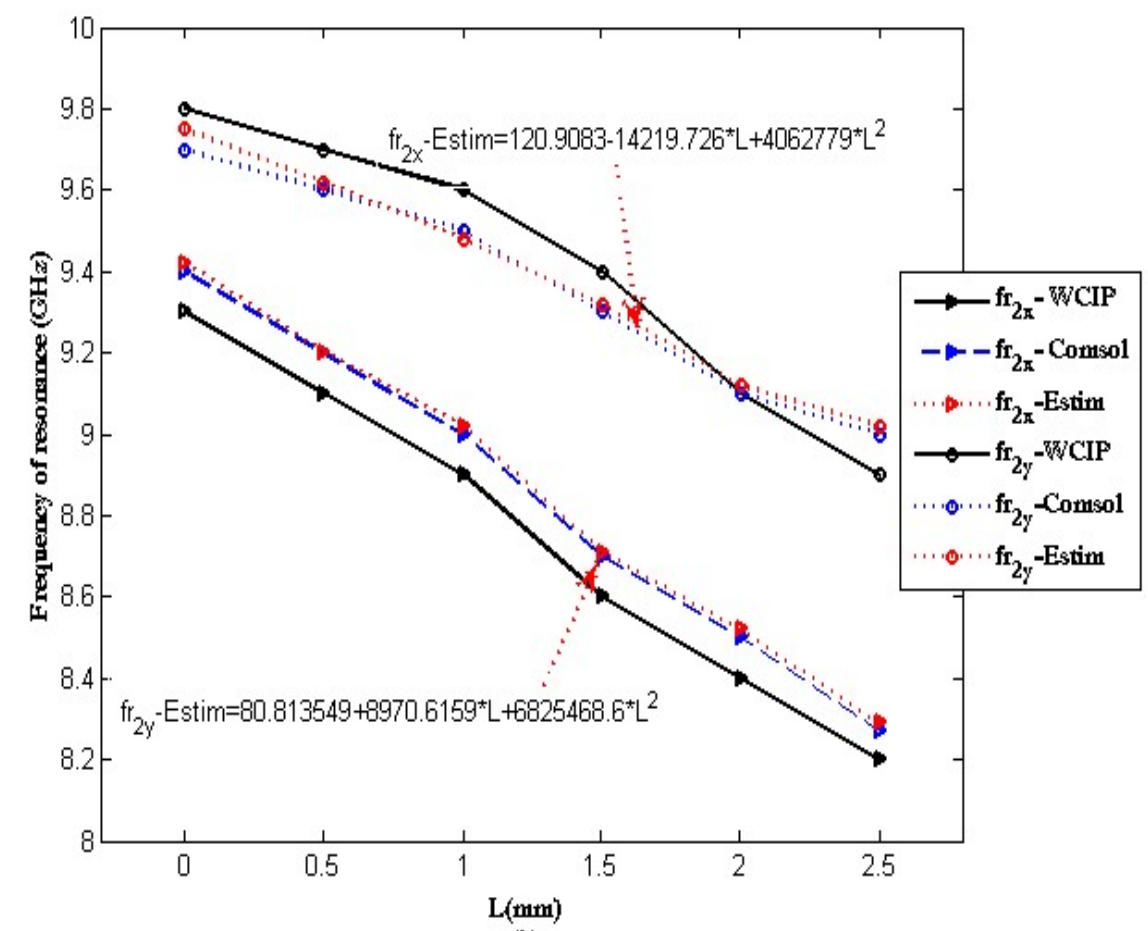

(b)

Fig. 12. The five resonant frequencies with the variations of the dimensions influenced. (a) $f_{1 x}, f_{3 x}$ and $f r_{1 y}$, (b) $f_{2 x}$, and $\mathrm{fr}_{2 \mathrm{y}}$

\section{L-NOTCHED RECTANGULAR METALLIC RING FSS EQUIVALENT STRUCTURE DETERMINATION} APPROACH

The dimensions affecting each resonant frequency of a complex metallic pattern FSS such as the notched quasi-square FSS are determined after achieving the parametric study of the structure. A deep comprehension of the FSS behavior leads to a determination of a simple equivalent circuit based on series LC components branches which are not all the time possible for all FSS structures. To overcome this drawback, equivalent FSS structures based on non-coupled parallel metallic strips are introduced which necessitate the presentation of an approximate approach determining the real or the physical length $\mathrm{L}_{\mathrm{r}}$, Fig. 1, of the metallic strip FSS to end with an FSS having the desired resonant frequency. First, the curve describing the relationship between the resonant frequency and the actual length of the strip $L_{r}$ is plotted in Fig. 13, by recording the resonant frequency calculated by the WCIP method for different strip lengths $L_{r}$ varying from $5.25 \mathrm{~mm}$ until $15.75 \mathrm{~mm}$ with a step equal to $0.25 \mathrm{~mm}$, so that to cover the interval of $\mathrm{L}_{\mathrm{r}}$ values possible by the standard metallic strip FSS being $\mathrm{W}=1 \mathrm{~mm}$, the substrate dielectric constant $\varepsilon_{\mathrm{r}}=4.4$, the substrate thickness $\mathrm{h}=1 \mathrm{~mm}$, the dimensions of the basic unit cell are $\mathrm{a} \times \mathrm{b}=20 \mathrm{~mm} \times 20 \mathrm{~mm}$ as shown in Fig. 11.

A comparative study is made to estimate the actual strip's length $L_{r}$ having a specific resonant frequency and this by determining the curve that describes the relationship between the resonant frequency and the actual length as shown in Fig. 13. The blue circles concern the resonant frequency 
obtained by the WCIP method for a given strip's length $\mathrm{L}_{\mathrm{r}}$. The red curve is obtained by an interpolation process of the WCIP results.

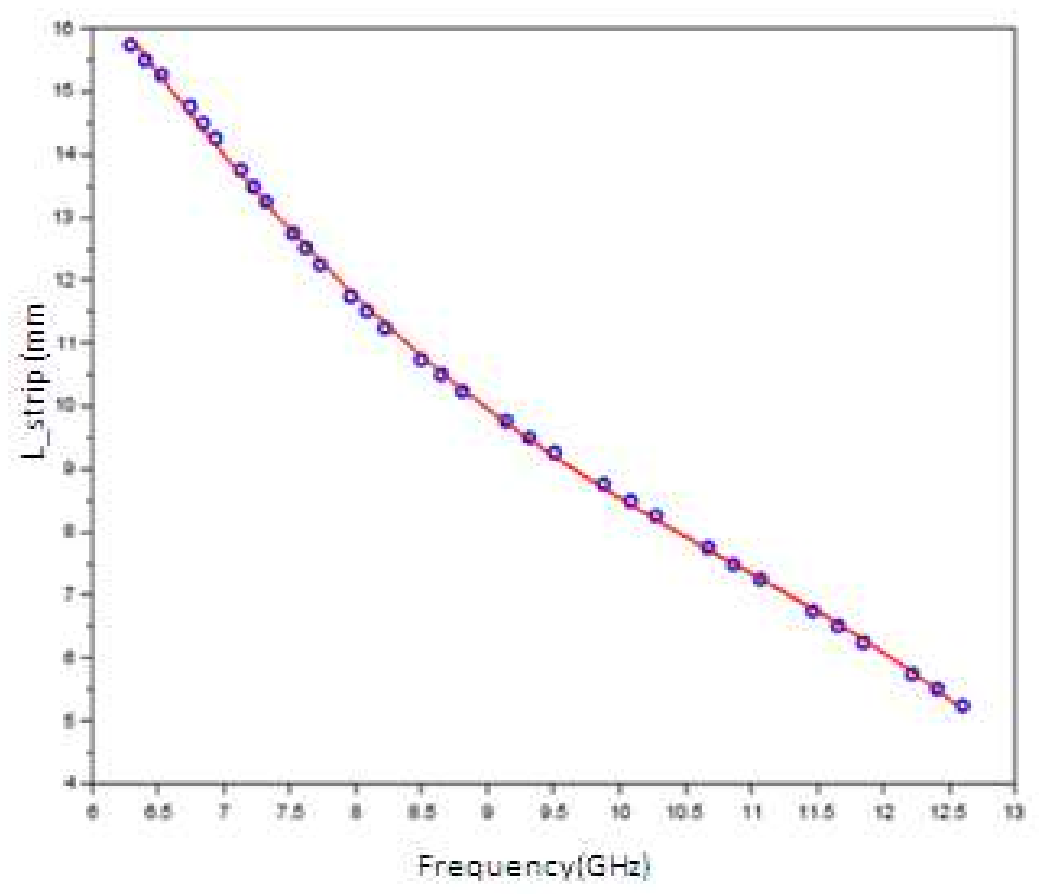

Fig. 13.Real metallic strip length of the FSS as a function of its resonant frequency.

From Fig. 13 the length $L_{r}$ can be determined for any value of the desired frequency varying from 6.29 to $12.60 \mathrm{GHz}$. To validate the approximate proposed approach, the measured resonant frequencies of three proposed FSS are used.

The first structure presents the unit cell of the notched rectangular metallic ring FSS shown in Fig. 3, where the resonant frequencies given by the system of measurement and considered as desired resonant frequencies for the presented approach are $8.4 \mathrm{GHz}$ and $10.1 \mathrm{GHz}$ when the incident wave is $x$-polarized and $7.8 \mathrm{GHz}$ when the incident wave is $y$-polarized. An FSS structure equivalent to the structure of Fig. 3 and based on two non-coupled metallic strips according to $x$ polarization with lengths $L_{l x}$ and $L_{2 x}$, and a single metallic strip according to y with length $L_{l y}$ is shown in Fig. 14.a.

The resonant frequencies given by the measurements and corresponding to the structure of Fig. 3 are replaced in Fig.13as desired resonant frequencies giving the real lengths of the strips as $L_{1 x=}$ $10.98 \mathrm{~mm}, L_{2 x}=8.41 \mathrm{~mm}, L_{1 y}=7.8 \mathrm{~mm}$. The basic FSS unit cell has dimensions of $a=20 \mathrm{~mm}$ and $b=20$ $\mathrm{mm}$, substrate dielectric constant of $\varepsilon_{r}=4.4$ and a thickness of $h=1 \mathrm{~mm}$.

The resonant frequencies obtained by the WCIP method when characterizing the equivalent FSS resulting from the presented synthesis approach are $8.2 \mathrm{GHz}$ and $10 \mathrm{GHz}$ when the incident wave is $x$-polarized and $7.8 \mathrm{GHz}$ when the incident wave is $y$-polarized as shown in Fig. 14.b. The relative error between the measured results of the notched quasi-square FSS of Fig. 1 and the results of the 
proposed equivalent FSS structure of Fig. 14 .a is $2.38 \%$ and $0.99 \%$ respectively in $x$-polarization and $0 \%$ iny-polarization.

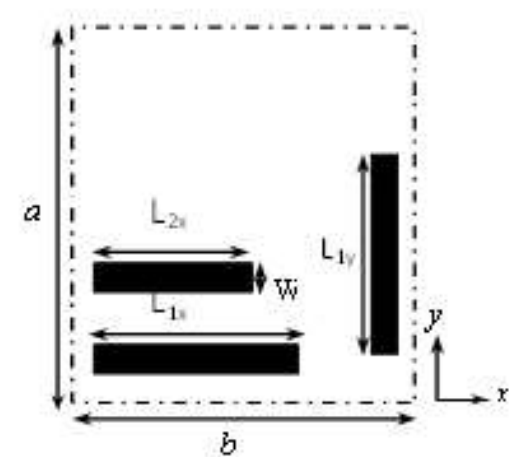

(a)

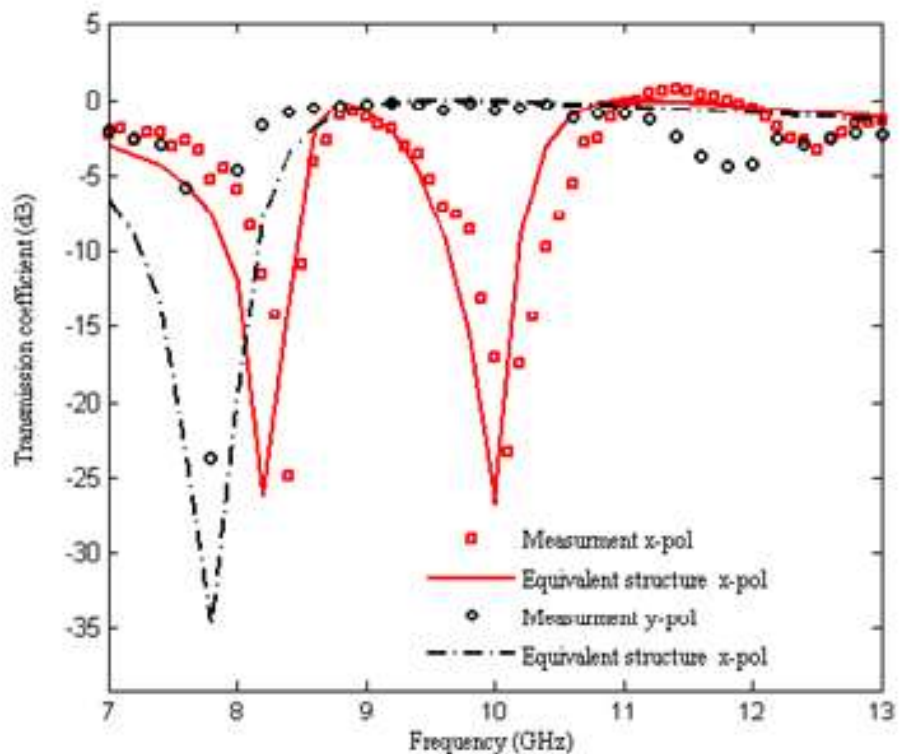

(b)

Fig. 14.(a) FSS Structure equivalent to the notched quasi-square FSS structure, (b) Simulated and measured transmission coefficient versus the operating frequency for the x-polarized source and the y-polarized source.

The same approach's steps are repeated to find the equivalent FSS structures of the open notched quasi-square metallic ring FSS proposed in [9] and shown in Fig. 15. The manufactured FSS are printed on a fiber glass (FR-4) substrate with dielectric constant $\varepsilon_{\mathrm{r}}=4.4$ and a thickness of $\mathrm{h}=1 \mathrm{~mm}$ [9].

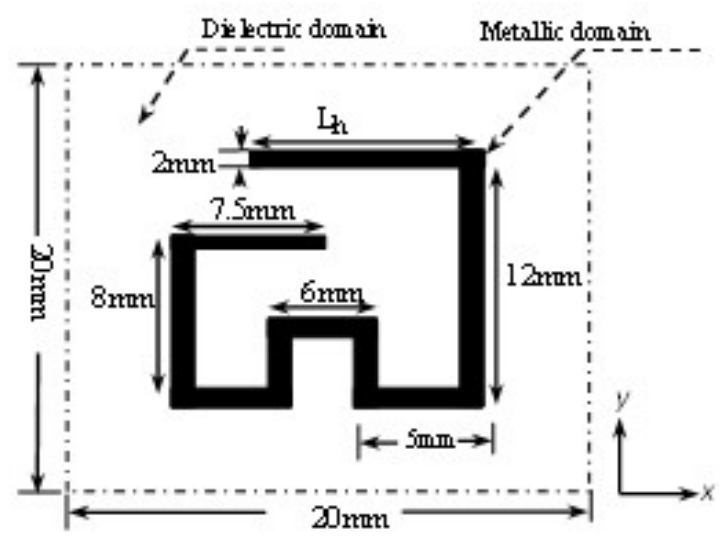

Fig.15. The open notched quasi-square metallic ring FSS with unit cell geometry [9].

Table I summarizes the different obtained parallel metallic strips lengths of the equivalent FSS structure corresponding to the measured resonant frequencies of the open notched quasi-square metallic ring FSS for $\mathrm{L}_{\mathrm{h}}=9.5 \mathrm{~mm}$ [9]. 
TABLE I: EQUIVALENT STRUCTURES STRIPS LENGTHS OF THE OPEN NOTCHED QUASI SQUARE METALLIC RING FSS WITH $\mathrm{LH}=9.5 \mathrm{MM}$.

\begin{tabular}{ccccc}
\hline & $\begin{array}{c}\text { Measured resonant } \\
\text { frequency }(\mathbf{G H z}) \text { of } \\
\text { the open notched } \\
\text { quasi square metallic } \\
\text { ring FSS }\end{array}$ & $\begin{array}{c}\text { real metallic strip } \\
\text { length } \mathrm{L}_{\mathbf{r}}(\mathbf{m m})\end{array}$ & $\begin{array}{c}\text { Equivalent metallic } \\
\text { strips FSS resonant } \\
\text { frequency }(\mathbf{G H z})\end{array}$ & Error \% \\
\hline$x$-polarized source & $\mathrm{fr}_{1 \mathrm{x}}=9.1$ & & \\
& $\mathrm{fr}_{2 \mathrm{x}}=9.9$ & $\mathrm{~L}_{1 \mathrm{x}}=9.6$ & $\mathrm{fr}_{1 \mathrm{x}}=9$ & 1.10 \\
$\mathrm{fr}_{3 \mathrm{x}}=11.7$ & $\mathrm{~L}_{2 \mathrm{x}}=8.67$ & $\mathrm{fr}_{2 \mathrm{x}}=10.2$ & 0.86 \\
\hline$y$-polarized source & $\mathrm{fr}_{1 \mathrm{y}}=6.7$ & $\mathrm{~L}_{3 \mathrm{x}}=6.49$ & $\mathrm{fr}_{1 \mathrm{y}}=6.6$ & 1.49 \\
\hline
\end{tabular}

The resulting equivalent FSS structure to the structure presented in Fig. 15 is based on three uncoupled parallel metallic strips, according to $x$-polarization with lengths $L_{1 x}, L_{2 x}$ and $L_{3 x}$ and a single metallic strip according to y polarization as shown in Fig.16.a.

When $\mathrm{L}_{\mathrm{h}}=11.5 \mathrm{~mm}$, the parallel metallic strips FSS structure equivalent to the open notched quasisquare metallic ring FSS of Fig. 15 is shown in Fig. 17.a. This structure is based on two metallic strips according to $x$-polarization with lengths $L_{1 x}$ and $L_{2 x}$ and two metallic strips according to $y$ polarization with length $L_{1 y}$ and $L_{2 y}$.

Table II summarizes the different obtained results for the strips lengths corresponding to the measured frequencies of the open notched quasi-square metallic ring FSS show in Fig.15 for $\mathrm{L}_{\mathrm{h}}=11.5 \mathrm{~mm}$.

TABLE II: EQUIVALENT STRUCTURES STRIPS LENGTHS OF THE OPEN NOTCHED QUASI-SQUARE METALLIC RING FSS WITH $\mathrm{LH}=11.5 \mathrm{MM}$

\begin{tabular}{lcccc}
\hline & $\begin{array}{c}\text { Measured resonant } \\
\text { frequency }(\mathbf{G H z}) \text { of } \\
\text { the open notched } \\
\text { quasi square metallic } \\
\text { ring FSS }\end{array}$ & $\begin{array}{c}\text { real metallic strip } \\
\text { length } \mathrm{L}_{\mathbf{r}}(\mathbf{m m})\end{array}$ & $\begin{array}{c}\text { Equivalent metallic } \\
\text { strips FSS resonant } \\
\text { frequency }(\mathbf{G H z})\end{array}$ & Error \% \\
\hline $\boldsymbol{x}$-polarized source & $\mathrm{fr}_{1 \mathrm{x}}=8.8$ & $\mathrm{~L}_{1 \mathrm{x}}=10.28$ & & \\
\hline $\boldsymbol{y}$-polarized source & $\mathrm{fr}_{2 \mathrm{x}}=11.7$ & $\mathrm{~L}_{2 \mathrm{x}}=6.49$ & $\mathrm{fr}_{1 \mathrm{xe}}=8.8$ & 0.86 \\
\hline & $\mathrm{fr}_{1 \mathrm{y}}=6.5$ & $\mathrm{~L}_{1 \mathrm{y}}=15.3$ & $\mathrm{fr}_{1 \mathrm{ye}}=6.4$ & 1.54 \\
$\mathrm{fr}_{2 \mathrm{y}}=8.8$ & $\mathrm{~L}_{2 \mathrm{y}}=10.28$ & 0 \\
\hline
\end{tabular}

The transmission coefficients of the equivalent FSS structure in addition to measured ones [9] of the open quasi-square metallic ring FSS for the $x$ and $y$ polarized excitations are given in Figs.16.b and 17.b for $\mathrm{L}_{\mathrm{h}}=9.5 \mathrm{~mm}$ and $\mathrm{L}_{\mathrm{h}}=11.5 \mathrm{~mm}$ respectively. The equivalent FSS structures results show a good agreement. 


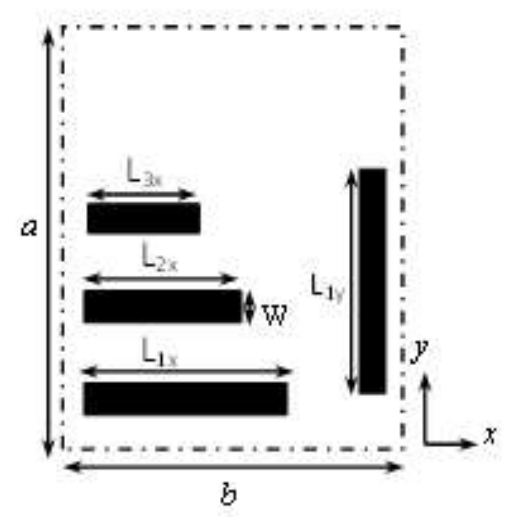

(a)

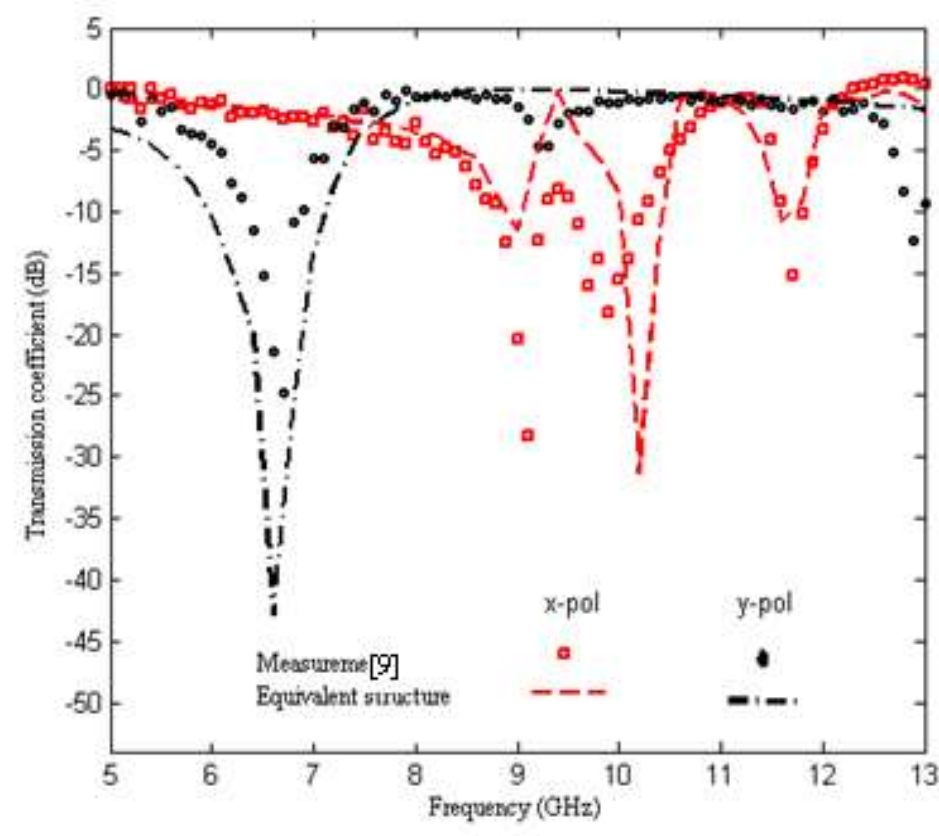

(b)

Fig. 16. (a) Equivalent structure, (b) Simulated and measured transmission coefficient versus the operating frequency for the x-polarized source and the y-polarized source for the structure with $\mathrm{L}_{\mathrm{h}}=9.5 \mathrm{~mm}$.

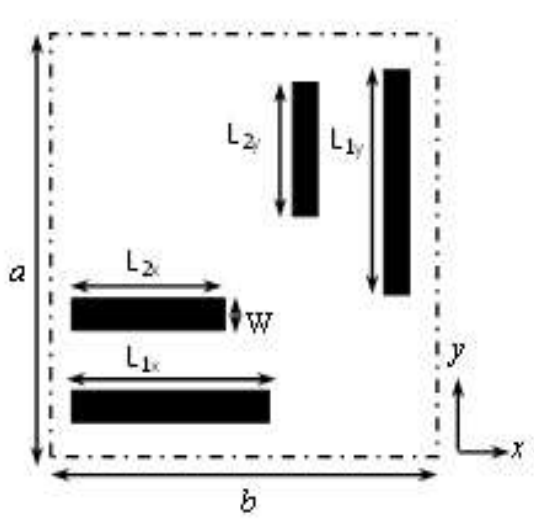

(a)

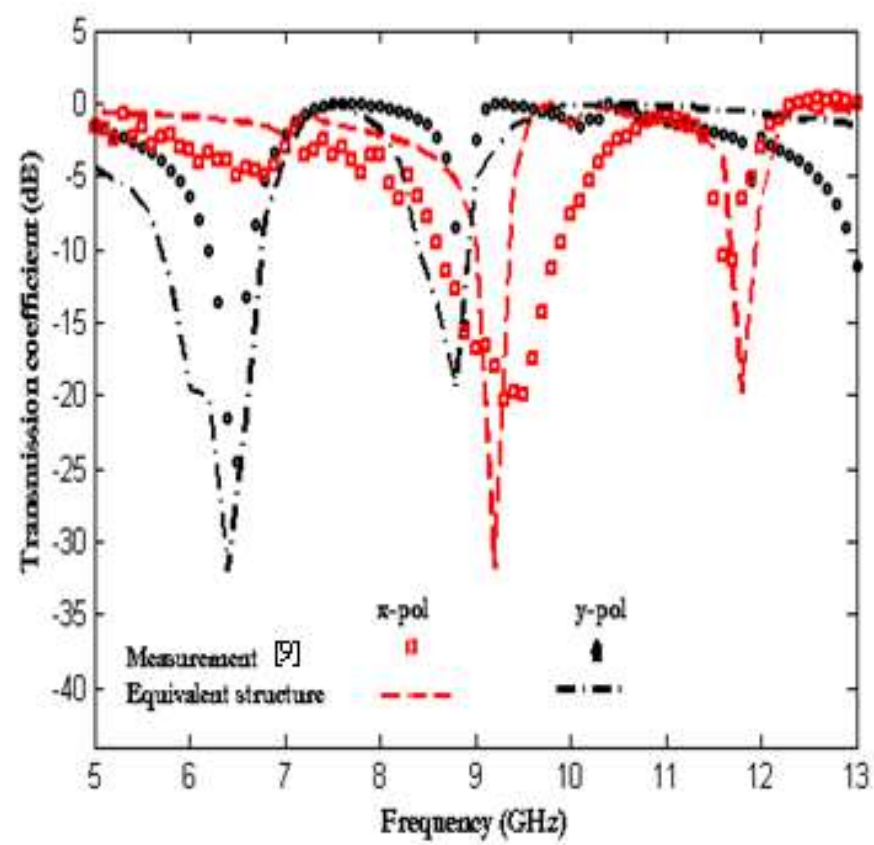

(b)

Fig. 17. (a) Equivalent structure, (b) Simulated and measured transmission coefficient versus the operating frequency for the x-polarized source and the y-polarized source for the structure with $\mathrm{L}_{\mathrm{h}}=11.5 \mathrm{~mm}$. 


\section{THE L-NOTCHED RECTANGULAR METALLIC RING FSS ABACUSES}

When the applications are restricted to a specific FSS pattern as that shown in Fig. 1, abacus can provide rapid precise results without a need to use neither software nor experimental measurements. In this part abacuses are proposed and used to extract the resonant frequencies of the L- notched rectangular metallic ring FSS structure but without doing any simulation.

So according to the parametric study of the FSS of Fig. 2, the resonance frequencies $\mathrm{fr}_{1 \mathrm{x}}, \mathrm{fr}_{3 \mathrm{x}}$ and $\mathrm{fr}_{1 y}$ depends on the length $\mathrm{L}_{\mathrm{h}}$ while $\mathrm{fr}_{2 \mathrm{x}}$ and $\mathrm{fr}_{2 \mathrm{y}}$ are varied according to $\mathrm{L}$.

Figs.18 and 19 show the effect of increasing the lengths $L_{h}$ and $L$ on L-notched rectangular metallic ring FSS resonant frequencies respectively.

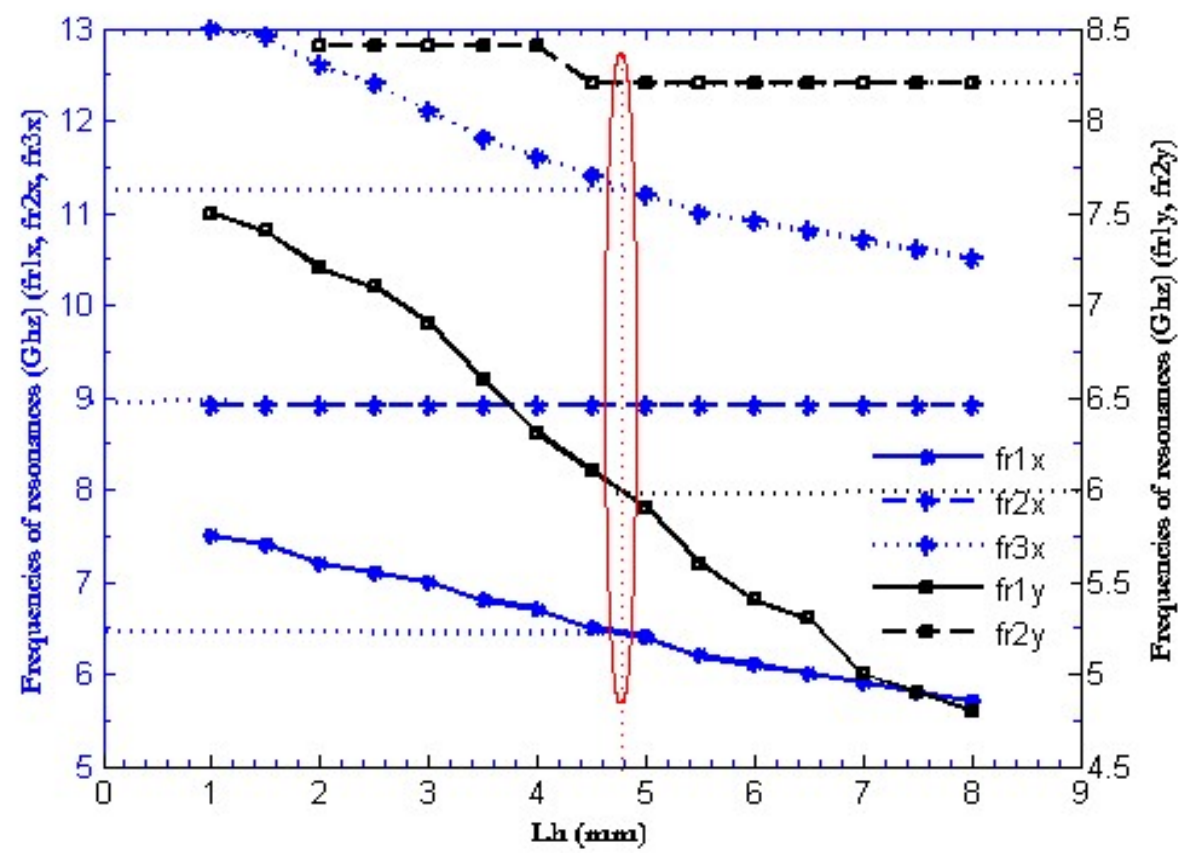

Fig. 18. The resonant frequencies versus the length $\mathrm{L}_{h}$ with $\mathrm{L}=2 \mathrm{~mm}$ and $\mathrm{L}_{\mathrm{v}}=4 \mathrm{~mm}$.

Figs. 18 and 19 can be used as abacus for the choice of the dimensions of the L- notched rectangular metallic ring FSS of Fig. 2providing desired resonant frequencies. According to Fig.18, the values of the resonant frequencies $\mathrm{fr}_{1 \mathrm{x}}, \mathrm{fr}_{2 \mathrm{x}}, \mathrm{fr}_{3 \mathrm{x}}, \mathrm{fr}_{1 \mathrm{y}}$ and $\mathrm{fr}_{2 \mathrm{y}}$ for a fixed value of the length $\mathrm{L}_{\mathrm{h}}=4.8 \mathrm{~mm}$ are respectively: $6.5 \mathrm{GHz}, 9 \mathrm{GHz}, 11.3 \mathrm{GHz}, 6 \mathrm{GHz}$ et $8.2 \mathrm{GHz}$.

The confirmation of this abacus approach results is done by simulating the resulting L- notched rectangular metallic ring FSS of Fig. 2 with $\mathrm{L}_{\mathrm{h}}=4.8 \mathrm{~mm}$ using COMSOL Multiphysics. The obtained results are illustrated in Fig. 20 for both the $x$ and $y$ polarizations of the normally incident plane wave source. The simulated resonant frequencies $\mathrm{fr}_{1 \mathrm{x}}, \mathrm{fr}_{2 \mathrm{x}}, \mathrm{fr}_{3 \mathrm{x}}, \mathrm{fr}_{1 \mathrm{y}}$ and $\mathrm{fr}_{2 \mathrm{y}}$ are respectively $6.5 \mathrm{GHz}$, 8.8 GHz, $11.2 \mathrm{GHz}, 6 \mathrm{GHz}$ and $8.2 \mathrm{GHz}$ with errors $0 \%, 2.22 \mathrm{GHz}, 0.89 \%, 0 \%$ and $0 \%$. 


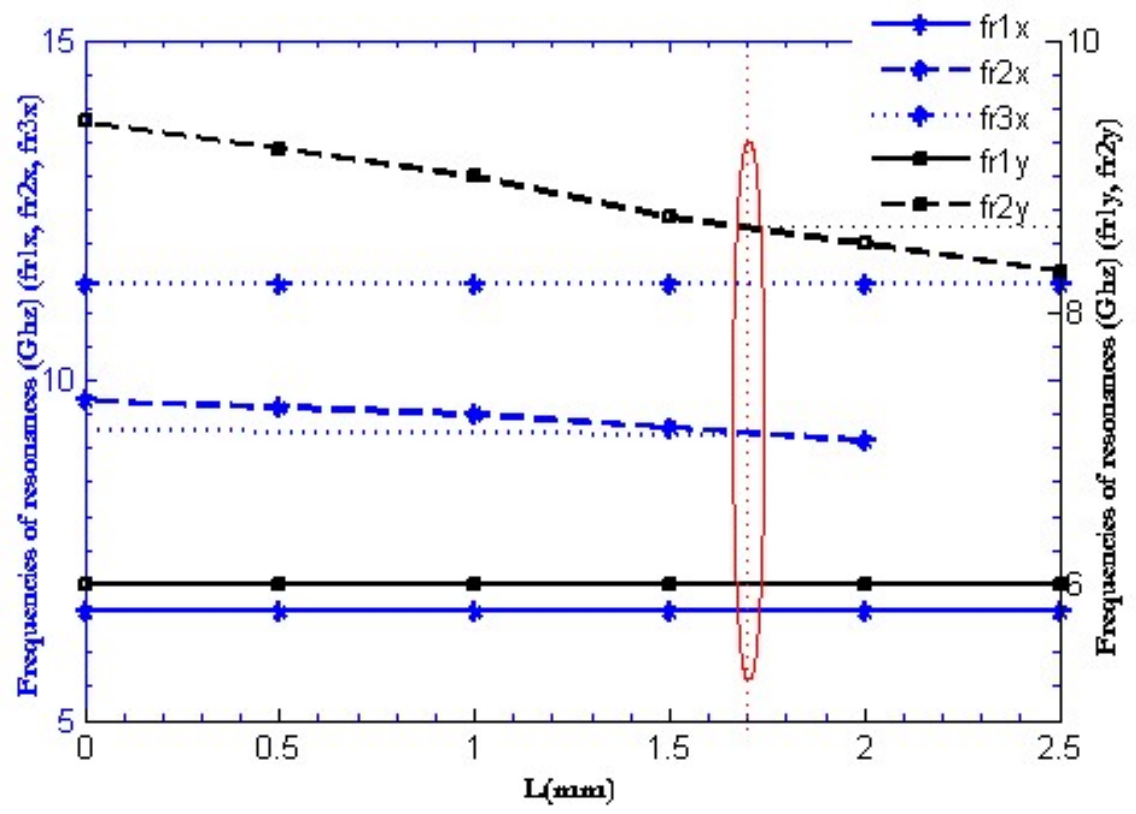

Fig. 19.The resonant frequencies versus the length $\mathrm{L}$ with $\mathrm{L}_{\mathrm{h}}=4.5 \mathrm{~mm}$ and $\mathrm{L}_{\mathrm{v}}=4 \mathrm{~mm}$.

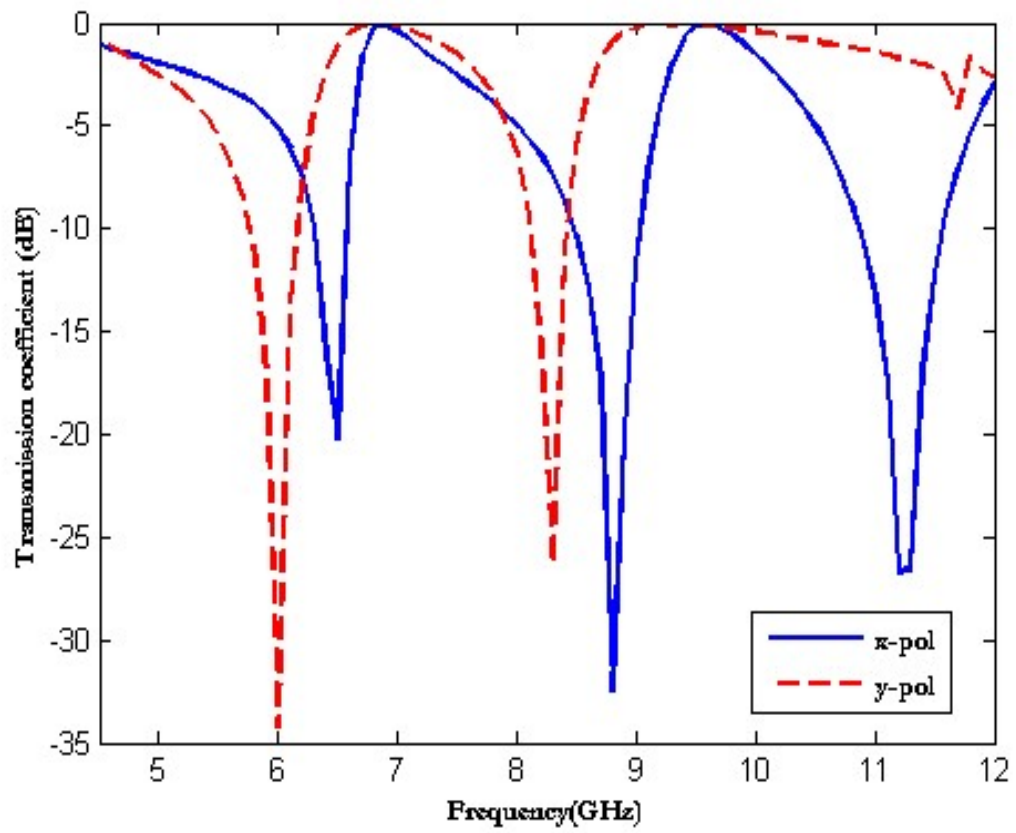

Fig. 20. Transmission coefficient versus frequency for $\mathrm{L}_{\mathrm{h}}=4.8 \mathrm{~mm} \mathrm{~L}=2 \mathrm{~mm}$ and $\mathrm{L}_{\mathrm{v}}=4 \mathrm{~mm}$.

For $\mathrm{L}$ fixed at $1.7 \mathrm{~mm}$ with $\mathrm{L}_{\mathrm{h}}=4.5 \mathrm{~mm}$ and $\mathrm{L}_{\mathrm{v}}=4 \mathrm{~mm}$, Fig. 19 is used to extract the corresponding resonant frequencies $\mathrm{fr}_{1 \mathrm{x}}, \mathrm{fr}_{2 \mathrm{x}}, \mathrm{fr}_{3 \mathrm{x}}, \mathrm{fr}_{1 \mathrm{y}}$ and $\mathrm{fr}_{2 \mathrm{y}}$. They are respectively $6.6 \mathrm{GHz}, 9.2$ $\mathrm{GHz}, 11.4 \mathrm{GHz}, 6 \mathrm{GHz}$ and $8.6 \mathrm{GHz}$. Then the FSS structure of Fig. 2 is simulated with COMSOL Multiphysics for the dimensions $\mathrm{L}=1.7 \mathrm{~mm}, \mathrm{~L}_{\mathrm{h}}=4.5 \mathrm{~mm}$ and $\mathrm{L}_{\mathrm{v}}=4 \mathrm{~mm}$ and the results of the scattering coefficients are shown in Fig. 21. The simulated resonant frequencies $\mathrm{fr}_{1 \mathrm{x}}, \mathrm{fr}_{2 \mathrm{x}}, \mathrm{fr}_{3 \mathrm{x}}, \mathrm{fr}_{1 \mathrm{y}}$ and $\mathrm{fr}_{2 \mathrm{y}}$ are respectively $6.6 \mathrm{GHz}, 9 \mathrm{GHz} 11.4 \mathrm{GHz} 6.1 \mathrm{GHz}$ and $8.6 \mathrm{GHz}$ with errors of $0 \%, 2.22 \%$, $0 \%, 1.63 \%$ and $0 \%$. 


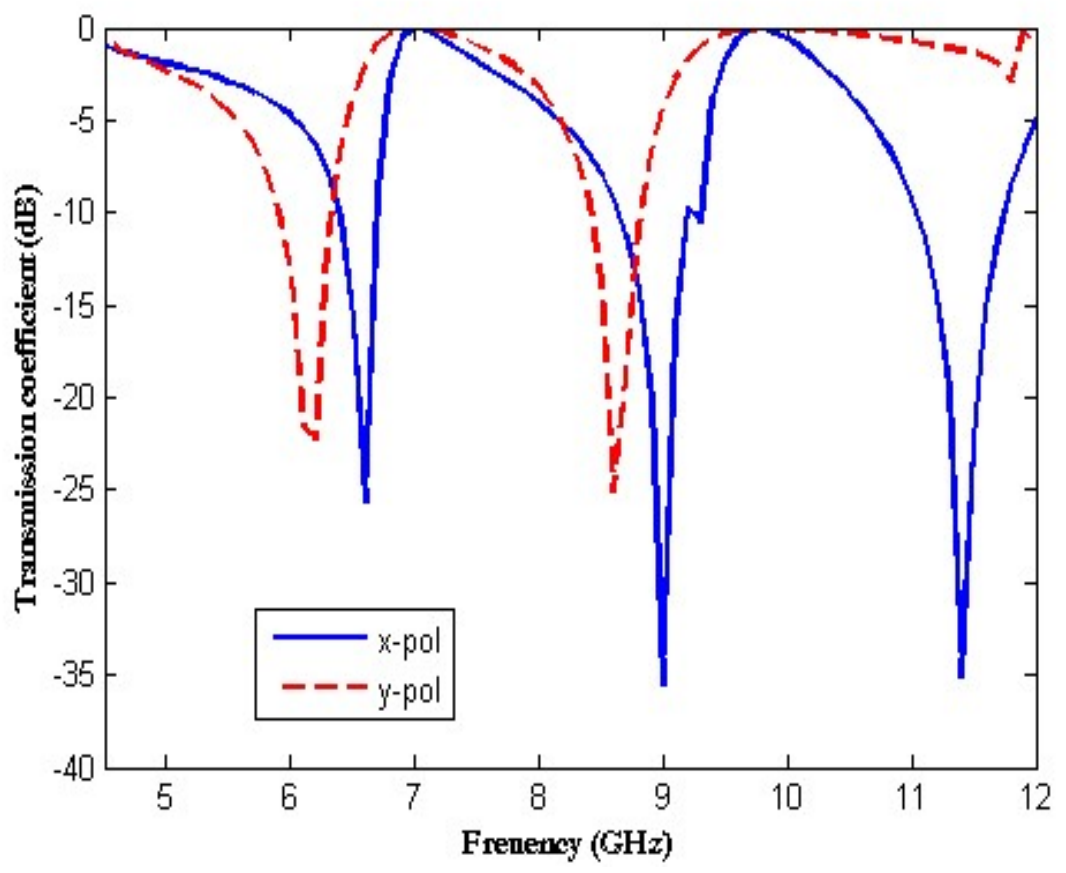

Fig. 21. Transmission coefficient versus frequency for $\mathrm{L}=1.7 \mathrm{~mm}, \mathrm{~L}_{h}=4.5 \mathrm{~mm}$ and $\mathrm{L}_{\mathrm{v}}=4 \mathrm{~mm}$.

\section{CONCLUSION}

In this paper, the L- notched rectangular metallic ring FSS is analyzed using WCIP method. The proposed FSS presents a frequency behavior that may be suitable in the design of multiband structures where the FSS can be used simultaneously for dual and three-band applications when the two perpendicular polarizations are considered. One FSS has been fabricated and characterized. The FSS resonant frequencies can be adjusted by changing the dimensions of the FSS determined by the parametric study. To determine the approximate equations of the different FSS resonant frequencies an approximate procedure is presented. In complex pattern FSS such as the open notched quasisquare metallic ring FSS the determination of an equivalent circuit based on resonant LC circuit offering a complete FSS behavior comprehension is quite difficult. Thus the approximate procedure is extended to determine the complex patterns FSS equivalent structures based on non-coupled parallel metallic strips that can replace the complex pattern FSS for given resonant frequencies. When the applications are limited to a specific FSS such as L- notched rectangular metallic ring FSS due to its availability in terms of cost and manufacturing, abacuses can be used to save time without a need to software. Two abacuses are plot and verified.

\section{REFERENCES}

[1] K. Sarabandi and N. Behdad, “A Frequency Selective Surface With Miniaturized Elements," IEEE Trans. Antennas Propag, vol. 55, no. 5, pp. 1239-1245, 2007.

[2] F. Dincer, K. Delihacioglu, M. Karaaslan, M. Bakir, and C. Sabah, "U-shaped frequency selective surfaces for 
single- and dual-band applications together with absorber and sensor configurations," IET Microwaves, Antennas Propag., vol. 10, no. 3, pp. 293-300, 2016.

[3] M. Titaouine, N. Raveu, A. G. Neto, and H. Baudrand, "dual-band and enhanced band fss characterization using the WCIP method," Microw. Opt. Technol. Lett, vol. 52, no. 4, pp. 836-839, 2010.

[4] J. Lee, M. Yoo, S. Member, and S. Lim, "A Study of Ultra-Thin Single Layer Frequency Selective Surface Microwave Absorbers With Three Different Bandwidths Using Double Resonance,” IEEE Trans. Antennas Propag., vol. 63, no. 1, pp. 221-230, 2015.

[5] A. L. P. S. Campos, F. C. G. da S. Segundo, R. H. C. Manicoba, and A. G. N. and A. G. D’Assuncao, “A Simple Fractal Geometry to Design Multi-Band Frequency Selective Surfaces," Microw. Opt. Technol. Lett, vol.54, no.10, pp 2321-2325, 2012.

[6] M. T. Letters, A. L. Pereira, S. Campos, U. Federal, R. Grande, U. Federal, R. Grande, R. Hebraico, C. Mani, and U. Estadual, "A Comparative Study of Two Numerical Techniques To Analyze Double Screen Frequency Selective Surface,” Microw. Opt. Technol. Lett, vol.55, no.9, pp 2206-2209, 2013.

[7] Y. Li, L. Li, Y. Zhang, and C. Zhao, "Design and synthesis of multilayer frequency selective surface based on antenna-filter-antenna using minkowski fractal structures," IEEE Trans. Antennas Propag., vol. 63, no. 1, pp. 133-141, 2015.

[8] D. H. Kim and J. I. Choi, "Design of a multiband frequency selective surface," ETRI .J, vol. 28, no. 4, pp. 506508, 2006.

[9] I. Adoui, M. Titaouine, H. Choutri, A. Djouimaa, T. Rolim De Sousa, A.G. Neto and Henri Baudrand, "Characterization of novel open notched quasi-square metallic ring FSS using WCIP method," Microw. Opt. Technol. Lett., vol. 58, no. 9, pp. 2071-2075, 2016.

[10] J. A. Bossard, D. H. Werner, T. S. Mayer, J. A. Smith, Y. U. Tang, R. P. Drupp, and L. Li, “The Design and Fabrication of Planar Multiband Metallodielectric Frequency Selective Surfaces for Infrared Applications," IEEE Trans. Antennas Propag., vol. 54, no. 4, pp. 1265-1276, 2006.

[11] D. Kim, J. Yeo, and J. Choi, “Compact Spatial Triple-Band-Stop Filter for Cellular / PCS / IMT-2000 Systems," ETRI J., vol. 30, no. 5, pp. 735-737, 2008

[12] M. Titaouine, N. Raveu, A. G. Neto, and H. Baudrand, "Electromagnetic Modeling of Quasi-Square Open Metallic Ring Frequency Selective Surface Using Wave Concept Iterative Procedure,” ETRI J., vol. 31, no. 1, pp. 77-79, 2009.

[13] I. Adoui, M. Titaouine, A.Djouimaa, H. Choutri and H. Baudrand, "WCIP Method Applied to Modeling a Modified Rectangular Metallic Ring FSS for Multiband Applications”, 7th seminar on Detection Systems: Architectures and Technologies (DAT'2017), 2017

[14] A. Djouimaa, M. Titaouine, I. Adoui, T. Rolim De Sousa, A. G. Neto and Henri Baudrand., "Tunable FSS simulation using WCIP method for multiband and dual polarized application", Radioelectronics and Communications Systems, vol. 60, no. 3, pp. 106-112, 2017.

[15] M. Aouissi, M. Titaouine, T. Rolim De Sousa, I. Adoui, A. G. Neto and Henri Baudrand, "Analysis of a joined split-ring FSS structure characterized by three resonant frequencies and a tuned enhanced band using the WCIP method", Turkish Journal of Electrical Engineering \& Computer Sciences, vol. 25, pp. 288- 2896, 2017.

[16] R. Saidi, M. Titaouine, A. Djouimaa, T. R. Sousa, A. G. Neto, K. Bencherif and H. Baudrand, "Characterization of Switchable Rectangular Ring FSS with Non Coupled Parallel Metallic Strips for Multi Band and Dual Polarized Applications Using WCIP Method", Journal of Microwave, Optoelectronics and Electromagnetic Applications, vol. 17, no. 1, pp. 102-120, March 2018.

[17] A. G. Neto, J. Costa, J. N. De Carvalho, A. Nascimento, C. B. De Aguiar, and D. F. Mamedes, "Analysis of Frequency Selective Surface with U-Shaped Geometry," Journal of Microwave, Optoelectronics and Electromagnetic Applications, vol. 14, no. SI-1, pp. SI113-SI122, 2015. 
Journal of Microwaves, Optoelectronics and Electromagnetic Applications, Vol. 17, No. 4, December 2018 DOI: http://dx.doi.org/10.1590/2179-10742018v17i41288

[18] M. O. L. Matekovits, G. C. Vietti Colomè, "Effect of transverse periodicity on the value of the effective dielectric constant for a microstrip line," IEEE Antennas Propag. Soc. AP-S Int. Symp., pp. 189-192, 2007.

[19] http://www.scilab.org/fr/download/latest. 